\title{
Early and current physical activity: relationship with intima-media thickness and metabolic variables in adulthood
}

\author{
Manoel C. S. Lima ${ }^{1,2}$, Maurício F. Barbosa ${ }^{3}$, Tiego A. Diniz ${ }^{2}$, \\ Jamile S. Codogno ${ }^{2}$, Ismael F. Freitas Júnior ${ }^{1,2}$, Rômulo A. Fernandes ${ }^{1,2}$
}

\begin{abstract}
Background: It is unclear whether early physical activity has a greater influence on intima-media thickness and metabolic variables than current physical activity. Objective: To analyze the relationship between current and early physical activity, metabolic variables, and intima-media thickness measures in adults. Method: The sample was composed of 55 healthy subjects of both sexes ( 33 men and 22 women). Total body fat and trunk fat were estimated by dual-energy X-ray absorptiometry. Carotid and femoral intima-media thickness were measured using a Doppler ultrasound device. A 12-hour fasting blood sample collection was taken (fasting glucose and lipid profile). Early physical activity was assessed through face-to-face interview, and the current physical activity was assessed by pedometer (Digi-Walker Yamax, SW200), which was used for a period of seven days. Results: Current physical activity was negatively related to total cholesterol $(\mathrm{rho}=-0.31)$, while early physical activity was negatively related to triglycerides $($ rho $=-0.42)$, total cholesterol ( $\mathrm{rho}=0.28)$, very low density lipoprotein $(\mathrm{rho}=0.44)$, and carotid intima-media thickness $(\mathrm{rho}=-0.50)$. In the multivariate model, subjects engaged in sports activities during early life had lower values of very low density lipoprotein $\left(b=8.74\left[b_{95 \% C I}=-16.1 ;-1.47\right]\right)$ and carotid intima-media thickness $(b=0.17$ [95\%CI: $\left.-0.28 ;-0.05]\right)$. Conclusion: Early physical activity has a significant influence on carotid intima-media thickness, regardless of the current physical activity.
\end{abstract} Keywords: maintenance of physical activity; physical activity; atherosclerosis; insulin resistance; movement.

\section{HOW TO CITE THIS ARTICLE}

Lima MCS, Barbosa MF, Diniz TA, Codogno JS, Freitas Júnior IF, Fernandes RA. Early and current physical activity: relationship with intima-media thickness and metabolic variables in adulthood. Braz J Phys Ther. 2014 Sept-Oct; 18(5):462-469. http://dx.doi. org/10.1590/bjpt-rbf.2014.0040

\section{Introduction}

In the last decades, the occurrences of obesity and cardiovascular diseases have increased among adults ${ }^{1}$. Similarly, the burden of these outcomes on healthcare costs has increased dramatically ${ }^{2}$. It is recognized that obesity and metabolic variables are related to the increase in the intima-media thickness of blood vessels ${ }^{3-5}$. Therefore, in clinical settings, vessel intima-media thickness has been used as a tool to screen for vascular injury ${ }^{6}$ and cardiovascular diseases $^{7}$. Moreover, greater carotid intima-media thickness (CIT) is related to stroke, myocardial infarction $^{8}$, and atherosclerosis ${ }^{9,10}$.

In contrast, greater current physical activity has been associated with lower mortality and increased life expectance ${ }^{11}$, as well as lower CIT $^{12,13}$. In hypertensive subjects, physical activity attenuates CIT progression, which is explained in part by the reduction in cardiovascular risk factors ${ }^{14}$.

It has been documented that early physical activity (its maintenance during childhood and adolescence) seems to prevent cardiovascular and metabolic outcomes in adulthood ${ }^{15,16}$. However, it is unclear whether early physical activity has a greater influence on intima-media thickness and metabolic variables than current physical activity. Thus, the purpose of this study was to analyze the relationship between current/early physical activity, metabolic variables, and intima-media thickness measures in adults.

\footnotetext{
${ }^{1}$ Programa de Pós-Graduação em Ciências da Motricidade, Instituto de Biociências, Universidade Estadual Paulista (UNESP), Rio Claro, SP, Brazil ${ }^{2}$ Grupo de Investigação Científica Relacionada a Atividade Física (GICRAF), Laboratório de Investigação em Exercício (LIVE), Departamento de Educação Física, Universidade Estadual Paulista (UNESP), Presidente Prudente, SP, Brazil

${ }^{3}$ Programa de Pós-Graduação em Radiologia, Departamento de Radiologia e Diagnóstico por Imagem, Universidade Federal de São Paulo (UNIFESP), São Paulo, SP, Brazil

Received: 02/20/2014 Revised: 04/02/2014 Accepted: 04/25/2014
} 


\section{Method}

\section{Subjects}

The present study includes the baseline measures of a cohort study "Maintenance of physical activity throughout life and vascular stiffness in adults: cross-sectional analysis and cohort of 12 months", which is being conducted in Presidente Prudente, SP, Brazil (from 2013 to 2014). In this cohort study, the following inclusion criteria were adopted: (i) age between 30 and 50 years; (ii) no previous history of stroke or myocardial infarction; (iii) no amputation or visual problems related to diabetes mellitus (there were no diabetic subjects); (iv) no physical limitation that would affect physical activity; (v) classification as either persistently active (at least one year of supervised sports practice outside school in both childhood [age 7 to 10] and adolescence [age 11 to 17]) or persistently sedentary (no supervised sports practice outside school in both childhood and adolescence); and (vi) informed consent.

In the selected sample, there were two hypertensive subjects under medical treatment (beta blocker), while $18.2 \%(n=10)$ reported the use of either statins or other medication. Among subjects with either hypertension or dyslipidemia there was no simultaneous use of two or more drugs (combination therapy). In additional analyses, there was no significant relationship between medicine use and the metabolic/cardiovascular variables and, therefore, these subjects were maintained in the sample.

The researcher responsible for the cohort study contacted fitness clubs of the city and also contacted the Human Resources Sector of the University to identify and contact eligible candidates to participate in the cohort. In the presented study, the sample was composed of 55 subjects of both sexes who fulfilled all inclusion criteria and, thus, were invited to participate in this study. All study procedures were approved by the Ethical Research Group of Universidade Estadual Paulista (UNESP), Presidente Prudente, SP, Brazil (approval no 173.571/2012), and all subjects signed an informed consent form.

\section{Anthropometry and body composition}

Body weight was measured using a digital scale (Filizola, PL-200, to the nearest $0.1 \mathrm{Kg}$ ) and height was measured with a wall-mounted stadiometer (to the nearest $0.1 \mathrm{~cm}$ ) with a maximum length of $220 \mathrm{~cm}$ (Sanny, Standard ES2030). Body mass index (BMI $\left[\mathrm{Kg} / \mathrm{m}^{2}\right]$ ) was calculated by the use of body weight and height values. Waist circumference was measured in centimeters $(\mathrm{cm})$ using a metallic tape.
All anthropometric measures were made in a reserved room following standard methods.

Total body and trunk fat were estimated by a Dual-Energy X-ray Absorptiometry (DEXA) scanner (Lunar DPX-NT; General Electric Healthcare, Little Chalfont, Buckinghamshire, UK), version 4.7. All participants were in light clothing, with no shoes or metal belongings on the body, and in supine throughout the examination (approximately 15 minutes). Total body and trunk fat were expressed in percentage values by the DEXA software. All measurements were carried out at the University laboratory in a controlled temperature room. Each morning, before the beginning of the measurements, the DEXA was calibrated by the same researcher, according to the references provided by the manufacturer.

\section{Intima-media thickness measurement}

To measure the carotid and femoral intimamedia thickness (CIT and FIT, respectively), we used a Doppler ultrasound device (Toshiba Xario, SSA-660A). All tests were performed at a hospital in morning (between 8 and $11 \mathrm{am}$ ), and analyses were performed by a medical doctor specializing in diagnostic imaging. The procedures adopted for the examinations followed the recommendations of the Brazilian Society of Radiology ${ }^{17}$. Prior to the examination, all subjects were at rest, lying in a supine position in a quiet room and acclimatized. To measure CIT, the neck was positioned in hyperextension and slightly inclined at $45^{\circ}$. The measurements were taken from the posterior wall of the artery, farthest from the transducer, manually and with the caliper method. Three measurements of CIT and FIT were obtained in the stretch of $15 \mathrm{~mm}$ free of plaques, where the pattern is clearly observed. For analysis of the results, we considered the mean values in millimeters $(\mathrm{mm})$ of each artery.

\section{Blood samples}

All blood sample collections and biochemical analyses were done in a private laboratory, which meets the standardization criteria of quality control adopted by the Brazilian Health Ministry. A 12-hour fasting blood sample collection was taken. Samples were collected in vacuum tubes containing gel with anticoagulant. Then the blood was centrifuged for 10 minutes at 3,000 rpm. To measure fasting glucose, total cholesterol (TC), triglycerides (TG), very low density lipoprotein cholesterol (VLDL-C), low density lipoprotein cholesterol (LDL-C), and high density lipoprotein cholesterol (HDL-C), 
an enzymatic colorimetric kit processed in an Autohumalyzer A5 unit was used ${ }^{18}$.

To obtain glycated hemoglobin $\left(\mathrm{HbA}_{1 \mathrm{C}}\right)$, blood was collected under vacuum in sealed tubes containing ethylenediaminetetraacetic acid (EDTA) as lyophilized anticoagulant. The determination of the glycated hemoglobin was performed in primary tube by high performance liquid chromatography (HPLC) equipment in D10 - Hemoglobin A1C Testing System (Bio-Rad ${ }^{\circledR}$, France). HPLC is a standardized methodology for $\mathrm{HbA}_{1 \mathrm{C}}$ determination, certified by the National Glycohemoglobin Standardization Program (NGSP) traceability of analytical performance with the reference methods Diabetes Control and Complications Trial (DCCT) and United Kingdom Prospective Diabetes Study Group (UKPDS) ${ }^{19,20}$.

\section{Early and current physical activity}

Early physical activity was assessed using two questions ${ }^{15,16}$ : (i) "Outside school, did you engage in any organized/supervised sport activities in clubs for at least 1 year between the ages of 7 and 10 years?" and (ii) "Outside school, did you engage in any organized/supervised sport activities in clubs for at least 1 year between the ages of 11 and 17 years?" Other physical activities, such as dance modalities (e.g. ballet), were also included. Subjects were classified as persistently active (sports practice in both childhood and adolescence [ $\mathrm{n}=45]$ ) or persistently sedentary (no sports practice in both childhood and adolescence $[\mathrm{n}=10])$.

Current physical activity was assessed by pedometer (Digi-Walker Yamax, SW200). The pedometer was fixed laterally at the hip and taken off only during periods of sleep, activities in the pool, and during shower. The pedometer was used for a period of seven days. At the end of each day, the subjects recorded the number of steps taken throughout the day. In the morning, to begin collecting the data, the "reset" button was pushed to zero out the equipment. The mean values of steps in the week were assigned as the level of current physical activity, and the sample was stratified as either physically active $(\geq 10,000$ steps/day $[n=21])$ or sedentary $(<10,000$ steps/day $[\mathrm{n}=34])^{21}$.

\section{Potential confounders}

Face-to-face interview was used to assess the regular use of anti-hypertensive drugs, lipidlowering drugs, and anti-diabetic drugs (statistical analysis was carried out using the number of drugs reported). Additionally, resting systolic and diastolic blood pressures (SBP and DBP, respectively) were measured at rest in a seated position after at least 10 minutes of rest. Medicine use and blood pressure measures were used as potential confounders, and multivariate models were adjusted by both variables.

\section{Statistical analysis}

Several variables presented non-parametric distribution and, thus, median and interquartile range (IR) were used as descriptive statistics. Mann-Whitney's test compared fat, metabolic, and cardiovascular variables according to current and early physical activity. Spearman's rank-order correlation (rho) analyzed the relationship between CIT/FIT and independent variables (Spearman's rank order correlation was used even in dataset with normal distribution). Finally, the linear regression model was used (expressed as beta values [b] and $95 \%$ confidence interval $\left.\left[b_{95 \% \mathrm{CI}}\right]\right)$, in which the statistically significant relationships in the multivariate model were adjusted simultaneously for potential confounders (sex, age, body fat, blood pressure, medicine use, and trunk fat). All analysis were performed by the statistical software BioEstat (release 5.0 [BioEstat, Tefé, Amazonas]), and the statistical significance was set at $p$-value $<0.05$.

\section{Results}

The sample was composed of 33 men and 22 women (Table 1). In the overall sample, the prevalence of insufficient current physical activity was $38.2 \%(n=21)$ and only $18.2 \%(n=10)$ of the sample reported no sports practice during childhood and adolescence. Regarding current physical activity, only body fat $(p$-value $=0.025)$ and trunk fat $(p$-value $=0.046)$ were statistically different. Total cholesterol had marginal significance ( $p$-value $=0.050)$.

Adults who engaged in sports practice during childhood and adolescence had lower body fat $(p$-value $=0.001)$, trunk fat $(p$-value $=0.001)$, triglycerides $(p$-value $=0.002)$, total cholesterol $(p$-value $=0.036)$, and VLDL-C $(p$-value $=0.001)$ than non-engaged adults (Table 2). Moreover, CIT was significantly lower in persistently active adults ( $p$-value $=0.001$ ). Current physical activity was also increased in adults engaged in sports practice during childhood and adolescence $(p$-value $=0.001)$.

Regarding medicine use, lowering lipid drugs was negatively related to FIT (rho $=0.30 ; \mathrm{p}$-value $=0.024)$, but not CIT (rho= $0.11 ; p$-value $=0.412)$. Metabolic variables were not related to medicine use. Current 
Table 1. General characteristics of the sample stratified by current physical activity (Brazil, $n=55$ ).

\begin{tabular}{|c|c|c|c|}
\hline Variables & $\begin{array}{c}\geq 10,000 \text { steps } / \text { day }(\mathrm{n}=\mathbf{2 1}) \\
\text { Median }(\text { IR) }\end{array}$ & $\begin{array}{c}<10,000 \text { steps/day }(\mathrm{n}=34) \\
\text { Median (IR) }\end{array}$ & $p$-value \\
\hline $\mathrm{M} / \mathrm{F}$ & $14 / 7$ & $19 / 15$ & \\
\hline Age (years) & $37.9(6.3)$ & $38.9(12.4)$ & 0.132 \\
\hline Body weight (Kg) & $77.6(12.5)$ & $74.9(19.9)$ & 0.856 \\
\hline Height $(\mathrm{cm})$ & $173.5(11.1)$ & $174.2(18.7)$ & 0.829 \\
\hline BMI $\left(\mathrm{Kg} / \mathrm{m}^{2}\right)$ & $24.5(6.2)$ & $24.6(5.3)$ & 0.822 \\
\hline $\mathrm{WC}(\mathrm{cm})$ & $80.5(11.7)$ & $82.3(15.6)$ & 0.456 \\
\hline Body fat $(\%)$ & $23.1(9.5)$ & $29.6(10.3)$ & 0.025 \\
\hline Trunk fat (\%) & $27.8(8.3)$ & $33.1(12.1)$ & 0.046 \\
\hline Glucose (mg/dL) & $89.6(9.9)$ & $89.3(8.5)$ & 0.842 \\
\hline Triglycerides (mg/dL) & $77.1(43.6)$ & $98.1(72.2)$ & 0.194 \\
\hline Total cholesterol (mg/dL) & $184.7(49.6)$ & $203.5(58.8)$ & 0.050 \\
\hline HDL-C (mg/dL) & $50.8(9.3)$ & $53.1(16.1)$ & 0.253 \\
\hline LDL-C (mg/dL) & $118.4(42.1)$ & $130.1(40.6)$ & 0.163 \\
\hline LDL-C/HDL-C (mg/dL) & $2.34(1.2)$ & $2.34(1.2)$ & 0.579 \\
\hline VLDL-C (mg/dL) & $15.4(8.7)$ & $19.6(14.4)$ & 0.103 \\
\hline $\mathrm{HbA}_{1 \mathrm{c}}(\mathrm{mmol} / \mathrm{mol})$ & $5.3(0.5)$ & $5.3(0.6)$ & 0.747 \\
\hline $\operatorname{CIT}(\mathrm{mm})$ & $0.60(0.09)$ & $0.66(0.14)$ & 0.078 \\
\hline FIT (mm) & $0.48(0.06)$ & $0.51(0.10)$ & 0.138 \\
\hline Steps/day & $11,906.1(1718)$ & $8,286.1(2136)$ & 0.001 \\
\hline $\mathrm{SBP}(\mathrm{mmHg})$ & $110(20)$ & $111(20)$ & 0.810 \\
\hline DBP $(\mathrm{mmHg})$ & $80(10)$ & $81(10)$ & 0.529 \\
\hline
\end{tabular}

$\mathrm{M}=$ male; $\mathrm{F}=$ female; $\mathrm{BMI}=$ body mass index; $\mathrm{WC}=$ waist circumference; HDL-C $=$ high density lipoprotein cholesterol; $\mathrm{LDL}-\mathrm{C}=$ low density lipoprotein cholesterol; VLDL-C $=$ very low density lipoprotein cholesterol; $\mathrm{HbA}_{1 \mathrm{C}}=$ glycated hemogloblin; $\mathrm{CIT}=$ carotid intima-media thickness; $\mathrm{FIT}=$ femoral intima-media thickness; $\mathrm{SBP}=$ systolic blood pressure; $\mathrm{DBP}=$ diastolic blood pressure.

physical activity was negatively related to TC $($ rho $=-0.31)$. On the other hand, early physical activity was negatively related to $\mathrm{TG}(\mathrm{rho}=0.42)$, $\mathrm{TC}(\mathrm{rho}=-0.28)$, VLDL-C (rho $=-0.44)$, and CIT $($ rho $=0.50)$ (Table 3).

In the multivariate model, regarding current physical activity, the number of steps was negatively related to total cholesterol $\left(b=0.004\left[b_{95 \% \mathrm{CI}}=0.007\right.\right.$; -0.001]) regardless of sex, age, and body composition (Table 4). The same patterns had been identified among adults engaged in sport activities during early life, when considering VLDL-C $(b=-8.74$ $\left.\left[\mathrm{b}_{95 \% \mathrm{CI}}=-16.1 ;-1.47\right]\right)$ and CIT $(\mathrm{b}=-0.17[95 \% \mathrm{CI}$ : $-0.28 ;-0.05])$.

\section{- Discussion}

This was a cross-sectional study in which early and current physical activity were related to cardiovascular and metabolic outcomes. It identified that early physical activity seems to be a determinant factor in the occurrence of increased cardiovascular risk, regardless of current physical activity.

In the present study, current physical activity was negatively related to total cholesterol, regardless of body fat (general and abdominal obesity). Regular walking (between $11 \mathrm{~km}$ and $16 \mathrm{~km}$ per week) during adulthood has been pointed out as effective in the control of different lipid parameters ${ }^{22}$, but previous studies have reported that this protective effect is mainly mediated by modifications in body composition ${ }^{23,24}$. In our sample, total body and trunk fat were both positively related to CIT (rho $=0.36$; $\mathrm{p}$-value $=0.003$ and $\mathrm{rho}=0.40 ; \mathrm{p}$-value $=0.002$, respectively) and total cholesterol (rho $=0.39$; $\mathrm{p}$-value $=0.003$, only trunk fat). Although obesity plays a central role in the development of metabolic and cardiovascular diseases due its pro-inflammatory action $^{23,24}$, our findings ratify that regular physical activity in daily life (not necessarily physical exercise) can be used as a public health strategy 
Table 2. General characteristics of the sample stratified by maintenance of sport activity during childhood and adolescence (Brazil, $\mathrm{n}=55)$.

\begin{tabular}{|c|c|c|c|}
\hline Variables & $\begin{array}{c}\text { Persistently Active }(\mathrm{n}=45) \\
\text { Median (IR) }\end{array}$ & $\begin{array}{c}\text { Persistently Sedentary }(\mathrm{n}=10) \\
\text { Median (IR) }\end{array}$ & $p$-value \\
\hline $\mathrm{M} / \mathrm{F}$ & $29 / 16$ & $4 / 6$ & \\
\hline Age (years) & $38.3(6.9)$ & $43.8(13)$ & 0.121 \\
\hline Body weight (Kg) & $77.3(17)$ & $74.8(17.5)$ & 0.639 \\
\hline Height (cm) & $174.1(12.8)$ & $166.3(18.5)$ & 0.015 \\
\hline BMI $\left(\mathrm{Kg} / \mathrm{m}^{2}\right)$ & $24.3(4.8)$ & $26.1(9.4)$ & 0.190 \\
\hline $\mathrm{WC}(\mathrm{cm})$ & $80.5(13.2)$ & $88.5(21.5)$ & 0.210 \\
\hline Body fat $(\%)$ & $24.1(10.5)$ & $40.2(17.6)$ & 0.001 \\
\hline Trunk fat (\%) & $31.3(8.2)$ & $47.9(14.6)$ & 0.001 \\
\hline Glucose (mg/dL) & $89.3(9.1)$ & $91.1(11.5)$ & 0.413 \\
\hline Triglycerides (mg/dL) & $76.2(46.9)$ & $127.7(36.8)$ & 0.002 \\
\hline Total cholesterol (mg/dL) & $190.1(47.8)$ & $225.4(54.2)$ & 0.036 \\
\hline HDL-C (mg/dL) & $52.5(12.3)$ & $50.1(19.9)$ & 0.793 \\
\hline LDL-C (mg/dL) & $123.2(40.2)$ & $132.3(38.2)$ & 0.385 \\
\hline LDL-C/HDL-C (mg/dL) & $2.3(1.2)$ & $2.7(1.3)$ & 0.789 \\
\hline VLDL-C (mg/dL) & $15.2(9.3)$ & $25.5(7.4)$ & 0.001 \\
\hline $\mathrm{HbA}_{1 \mathrm{c}}(\mathrm{mmol} / \mathrm{mol})$ & $5.3(0.5)$ & $5.3(0.8)$ & 0.637 \\
\hline CIT (mm) & $0.60(0.11)$ & $0.78(0.11)$ & 0.001 \\
\hline FIT (mm) & $0.49(0.08)$ & $0.53(0.12)$ & 0.287 \\
\hline Steps/day & $9,476.1(3148)$ & $6,848.8(4474)$ & 0.001 \\
\hline $\mathrm{SBP}(\mathrm{mmHg})$ & $110(20)$ & $105(30)$ & 0.920 \\
\hline DBP (mmHg) & $80(10)$ & $75(20)$ & 0.885 \\
\hline
\end{tabular}

$\mathrm{M}=$ male; $\mathrm{F}=$ female; $\mathrm{BMI}=$ body mass index; $\mathrm{WC}=$ waist circumference; HDL-C= high density lipoprotein cholesterol; LDL-C= low density lipoprotein cholesterol; VLDL-C $=$ very low density lipoprotein cholesterol; $\mathrm{HbA}_{\mathrm{IC}}=$ glycated hemogloblin; $\mathrm{CIT}=$ carotid intima-media thickness; FIT = femoral intima-media thickness; $\mathrm{SBP}=$ systolic blood pressure; $\mathrm{DBP}=$ diastolic blood pressure.

Table 3. Relationship between current/early physical activity, intimal thickness, and metabolic variables in adults (Brazil, $\mathrm{n}=55)$.

\begin{tabular}{lccccccccccc}
\hline \multirow{2}{*}{ Physical Activity } & Glucose & TG & TC & HDL-C & LDL-C & LDL-C/ & HDL-C & VLL-C & HbA & CIT & FIT \\
& Rho & rho & rho & Rho & Rho & rho & rho & rho & rho & rho \\
Current & 0.01 & -0.22 & $-0.31^{*}$ & -0.20 & -0.19 & -0.02 & -0.24 & -0.07 & -0.26 & -0.02 \\
Early & -0.11 & $-0.42^{\S}$ & $-0.28^{*}$ & -0.03 & -0.11 & -0.03 & $-0.44 \S$ & -0.06 & $-0.50 \S$ & -0.08 \\
\hline
\end{tabular}

$*=p$-value $<0.05 ; \S=p$-value $<0.01$; Rho $=$ Spearman's rank correlation; $\mathrm{TG}=$ triglycerides; $\mathrm{TC}=$ total cholesterol; HDL-C $=$ high density lipoprotein cholesterol; LDL-C $=$ low density lipoprotein cholesterol; VLDL-C $=$ very low density lipoprotein cholesterol; $\mathrm{HbA}_{1 \mathrm{c}}=\mathrm{glycated}$ hemogloblin; CIT= carotid intima-media thickness; FIT = femoral intima-media thickness.

to prevent dyslipidemia in adults ${ }^{25}$, regardless of obesity status.

Regarding this inflammatory action of obesity on the human body ${ }^{23,24}$, it has been documented over the last decade that physical activity has significant antioxidant and anti-inflammatory effects ${ }^{26}$. Although less investigated in pediatric populations, this protective effect of exercise can counteract the inflammatory action of the adipose tissue ${ }^{26}$ in adults, regardless of changes in body composition. Corroborating this idea, a recent study identified that, in obese/overweight adolescents, body fat is related to higher inflammatory status and increased carotid intima-media thickness ${ }^{13}$. At the same time, the same sample of overweight/obese adolescents showed higher cardiorespiratory fitness significantly related to lower inflammation status identified by C-reactive protein and lower carotid intima-media thickness ${ }^{13}$. Therefore, the recent scientific literature has consistently pointed out that, regardless of obesity status, physical activity and cardiorespiratory fitness have a significant role in the control of inflammation 
Table 4. Adjusted relationship between current/early physical activity, carotid intimal-media thickness and metabolic variables in adults (Brazil, $\mathrm{n}=55)$.

\begin{tabular}{lccc}
\hline \multicolumn{1}{c}{$\begin{array}{c}\text { Relationship between variables } \\
\text { Independent }\end{array}$} & Model $-\mathbf{1}$ & $\begin{array}{c}\text { Model }-\mathbf{2} \\
\boldsymbol{\beta}\left(\boldsymbol{\beta}_{\mathbf{9 5} \% \mathrm{Cl}}\right)\end{array}$ \\
$\begin{array}{l}\text { Physical Activity } \\
\text { Current }\end{array}$ & TC & $\boldsymbol{\beta}\left(\boldsymbol{\beta}_{\mathbf{9 5} \% \mathrm{Cl}}\right)$ & $-0.004(-0.007 ;-0.001)$ \\
Physical activity & & $-0.004(-0.007 ;-0.001)$ & $-28.7(-85.8 ; 28.3)$ \\
Early & TG & $-42.6(-89.2 ; 3.94)$ & $-25.2(-56.1 ; 5.56)$ \\
Early & TC & $-26.3(-50.4 ;-2.21)$ & $-8.74(-16.1 ;-1.47)$ \\
Early & VLDL-C & $-10.1(-16.4 ;-3.87)$ & $-0.17(-0.28 ;-0.06)$ \\
Early & CIT & $-0.18(-0.26 ;-0.10)$ & - \\
\hline
\end{tabular}

$\mathrm{TG}=$ triglycerides $\mathrm{TC}=$ total cholesterol; VLDL-C $=$ very low density lipoprotein cholesterol; $\mathrm{CIT}=$ carotid intima-media thickness; Model-1= crude; Model-2 = adjusted by sex, age, general, trunk fat, medicine use, systolic and diastolic blood pressures; $95 \% \mathrm{CI}=95 \%$ confidence interval.

and, hence, prevention of atherosclerosis since early age.

In this sample, early physical activity was consistently related to lower lipid, cardiovascular, and adiposity values. Previous studies have reported that adults engaged in sports activities during childhood and adolescence have a decreased likelihood of reporting dyslipidemia, type 2 diabetes mellitus, and arterial hypertension ${ }^{15,16}$. There is limited data about the relationship between early physical activity and vessel thickness, but there is a longitudinal relationship between accumulated habitual physical activity throughout life (mainly moderate to high intensity) and lower arterial stiffness among adults ${ }^{27}$. In fact, the impact of current physical activity level on CIT progression is at least in part explained by the reduction in cardiovascular risk factors ${ }^{14}$, and it would be possible to assume that this protective effect is linked to the maintenance of physical activity throughout life ${ }^{15,16}$ because physical activity is sustained from early age to adulthood ${ }^{15}$.

In contrast, an unexpected finding caught our attention because, in an additional analysis, the relationship between early physical activity and CIT was simultaneously adjusted by all potential confounders previously used (age, sex, general adiposity, trunk fat) plus current physical activity and, surprisingly, the relationship remained statistically significant $(b=-0.17$ [95\%CI: $-0.28 ;-0.05]$; $\mathrm{p}$-value $=0.004)$. This finding seems to show that the relationship between early physical activity and CIT could be supported by other pathways and not just the maintenance from childhood/adolescence to adulthood, as previously hypothesized.

Given this unexpected finding, a new hypothesis had to be formulated and methodological questions were raised. Regarding the new hypothesis, the possible epigenetic effect of physical activity over risk factors for atherosclerosis (such as blood pressure) was considered. For example, people with polymorphisms related to hypertension development are more exposed to the development of the disease when they have a lower physical activity level, and this pattern has been identified in both childhood and adulthood ${ }^{28,29}$. From this viewpoint, the new hypothesis raises other relevant questions because it is not clear if this protective effect of physical activity occurs during childhood and remains into adulthood. Therefore, if this independent effect of early physical activity is confirmed, it opens the door to a new line of research, which denotes that the relationship between physical activity and human growth constitutes an area not entirely explored and, hence, not completely understood.

Limitations should be recognized. The crosssectional design constitutes the main limitation of the study and, therefore, the development of cohorts analyzing this issue is recommended. Moreover, we suggest that further studies analyzing the maintenance of physical activity should take into account inflammatory biomarkers (TNF-a, interleukin-6, C-reactive protein), other important behavioral risk factors (e.g. smoking, alcohol consumption, $\left.\operatorname{diet}^{30}\right)$, and possible polymorphisms. Finally, in this study, current physical activity in the last week was considered as habitual physical activity, but it is not clear how much this specific week represents the pattern of habitual physical activity performed in the last months/years.

\section{Conclusions}

In summary, it is possible to conclude that early physical activity performed during childhood and 
adolescence has a significant effect on lipid variables and carotid intima-media thickness in adulthood, regardless of current physical activity.

\section{Acknowledgement}

The Fundação de Amparo à Pesquisa do Estado de São Paulo (FAPESP; process 2012/18001-0), Brazil, Conselho Nacional de Desenvolvimento Científico e Tecnológico (CNPq, Process: 474484/2012-2), Brazil and UNILAB Laboratory from Presidente Prudente.

\section{References}

1. Won KB, Chang HJ, Kim HC, Jeon K, Lee H, Shin $\mathrm{S}$, et al. Differential impact of metabolic syndrome on subclinical atherosclerosis according to the presence of diabetes. Cardiovasc Diabetol. 2013;12(1):41. http://dx.doi. org/10.1186/1475-2840-12-41. PMid:23452437

2. Codogno JS, Fernandes RA, Sarti FM, Freitas Júnior IF, Monteiro HL. The burden of physical activity on type 2 diabetes public healthcare expenditures among adults: a retrospective study. BMC Public Health. 2011;11(1):275. http://dx.doi.org/10.1186/1471-2458-11275. PMid:21542924

3. Fujihara K, Suzuki H, Sato A, Kodama S, Heianza Y, Saito $\mathrm{K}$, et al. Carotid artery plaque and LDL-to-HDL cholesterol ratio predict atherosclerotic status in coronary arteries in asymptomatic patients with type 2 diabetes mellitus. J Atheroscler Thromb. 2013;20(5):452-64. http://dx.doi. org/10.5551/jat.14977. PMid:23363982

4. Jørgensen L, Jenssen T, Joakimsen O, Heuch I, Ingebretsen OC, Jacobsen BK. Glycated hemoglobin level is strongly related to the prevalence of carotid artery plaques with high echogenicity in nondiabetic individuals: the Tromsø study. Circulation. 2004;110(4):466-70. http://dx.doi. org/10.1161/01.CIR.0000136809.55141.3B. PMid:15249512

5. Raitakari OT, Juonala M, Kähönen M, Taittonen L, Laitinen T, Mäki-Torkko N, et al. Cardiovascular risk factors in childhood and carotid artery intima-media thickness in adulthood: the Cardiovascular Risk in Young Finns Study. JAMA. 2003;290(17):2277-83. http://dx.doi.org/10.1001/ jama.290.17.2277. PMid:14600186

6. Tomiyama H, Yamashina A. CAVI vs. pressure and stiffness gradients in the arterial tree. Hypertens Res. 2010;33(4):380. http://dx.doi.org/10.1038/hr.2010.4. PMid:20139922

7. Lorenz MW, von Kegler S, Steinmetz H, Markus HS, Sitzer M. Carotid intima-media thickening indicates a higher vascular risk across a wide age range: prospective data from the Carotid Atherosclerosis Progression Study (CAPS). Stroke. 2006;37(1):87-92. http://dx.doi. org/10.1161/01.STR.0000196964.24024.ea. PMid:16339465

8. O'Leary DH, Polak JF, Kronmal RA, Manolio TA, Burke GL, Wolfson SK Jr, et al. Carotid-artery intima and media thickness as a risk factor for myocardial infarction and stroke in older adults. N Engl J Med. 1999;340(1):1422. http://dx.doi.org/10.1056/NEJM199901073400103. PMid:9878640
9. Lorenz MW, Markus HS, Bots ML, Rosvall M, Sitzer M. Prediction of clinical cardiovascular events with carotid intima-media thickness: a systematic review and meta-analysis. Circulation. 2007;115(4):459-67. http:// dx.doi.org/10.1161/CIRCULATIONAHA.106.628875. PMid:17242284

10. Cheng KS, Tiwari A, Baker CR, Morris R, Hamilton G, Seifalian AM. Impaired carotid and femoral viscoelastic properties and elevated intima-media thickness in peripheral vascular disease. Atherosclerosis. 2002;164(1):113-20. http://dx.doi.org/10.1016/S00219150(02)00042-4. PMid:12119200

11. Wen CP, Wai JP, Tsai MK, Yang YC, Cheng TY, Lee $\mathrm{MC}$, et al. Minimum amount of physical activity for reduced mortality and extended life expectancy: a prospective cohort study. Lancet. 2011;378(9798):124453. http://dx.doi.org/10.1016/S0140-6736(11)60749-6. PMid:21846575

12. Pahkala K, Heinonen OJ, Simell O, Viikari JS, Rönnemaa $\mathrm{T}$, Niinikoski H, et al. Association of physical activity with vascular endothelial function and intima-media thickness. Circulation. 2011;124(18):1956-63. http:// dx.doi.org/10.1161/CIRCULATIONAHA.111.043851. PMid:21969011

13. Silva LR, Cavaglieri C, Lopes WA, Pizzi J, Coelho-e-Silva MJ, Leite N. Endothelial wall thickness, cardiorespiratory fitness and inflammatory markers in obese and nonobese adolescents. Braz J Phys Ther. 2014;18(1):47-55. http://dx.doi.org/10.1590/S1413-35552012005000133. PMid:24675912

14. Palatini P, Puato M, Rattazzi M, Pauletto P. Effect of regular physical activity on carotid intima-media thickness. Results from a 6-year prospective study in the early stage of hypertension. Blood Press. 2011;20(1):37-44. http:// dx.doi.org/10.3109/08037051.2010.524080. PMid:20977389

15. Fernandes RA, Zanesco A. Early physical activity promotes lower prevalence of chronic diseases in adulthood. Hypertens Res. 2010;33(9):926-31. http://dx.doi. org/10.1038/hr.2010.106. PMid:20574424

16. Fernandes RA, Christofaro DG, Casonatto J, Codogno JS, Rodrigues EQ, Cardoso ML, et al. Prevalence of dyslipidemia in individuals physically active during childhood, adolescence and adult age. Arq Bras Cardiol. 2011;97(4):317-23. http://dx.doi.org/10.1590/S0066782X2011005000083. PMid:21830000

17. Sociedade Brasileira de Cardiologia. Normatização dos Equipamentos e das Técnicas para a Realização de Exames de Ultra-Sonografia Vascular. Arq Bras Cardiol. 2004;82(Suppl 6):S1-14.

18. Human RP, Jones GA. Evaluation of swab transport systems against a published standard. JClin Pathol. 2004;57(7):762-3. http://dx.doi.org/10.1136/jcp.2004.016725. PMid:15220372

19. Little RR, England JD, Wiedmeyer HM, Goldstein DE. Effects of whole blood storage on results for glycosylated hemoglobin as measured by ion-exchange chromatography, affinity chromatography, and colorimetry. Clin Chem. 1983;29(6):1113-5. PMid:6851106.

20. Panzer S, Kronik G, Lechner K, Bettelheim P, Neumann E, Dudczak R. Glycosylated hemoglobins (GHb): an 
index of red cell survival. Blood. 1982;59(6):1348-50. PMid:7082831.

21. Tudor-Locke C, Craig CL, Brown WJ, Clemes SA, De Cocker $\mathrm{K}$, Giles-Corti B, et al. How many steps/day are enough? For adults. Int J Behav Nutr Phys Act. 2011;8(1):79. http:// dx.doi.org/10.1186/1479-5868-8-79. PMid:21798015

22. Kraus WE, Slentz CA. Exercise training, lipid regulation, and insulin action: a tangled web of cause and effect. Obesity (Silver Spring). 2009;17(3s, Suppl 3):S21-6. http:// dx.doi.org/10.1038/oby.2009.384. PMid:19927141

23. Van Gaal LF, Mertens IL, De Block CE. Mechanisms linking obesity with cardiovascular disease. Nature. 2006;444(7121):875-80. http://dx.doi.org/10.1038/ nature05487. PMid: 17167476

24. Huang PL. eNOS, metabolic syndrome and cardiovascular disease. Trends Endocrinol Metab. 2009;20(6):295-302. http://dx.doi.org/10.1016/j.tem.2009.03.005. PMid:19647446

25. Lee IM, Shiroma EJ, Lobelo F, Puska P, Blair SN, Katzmarzyk PT et al. Effect of physical inactivity on major non-communicable diseases worldwide: an analysis of burden of disease and life expectancy. Lancet. 2012;380(9838):219-29. http://dx.doi.org/10.1016/S01406736(12)61031-9. PMid:22818936

26. Teixeira-Lemos E, Nunes S, Teixeira F, Reis F. Regular physical exercise training assists in preventing type 2 diabetes development: focus on its antioxidant and anti-inflammatory properties. Cardiovasc Diabetol. 2011;10(1):12. http://dx.doi.org/10.1186/1475-2840-10-12. PMid:21276212

27. van de Laar RJ, Ferreira I, van Mechelen W, Prins MH, Twisk JW, Stehouwer CD. Lifetime vigorous but not light-to-moderate habitual physical activity impacts favorably on carotid stiffness in young adults: the amsterdam growth and health longitudinal study. Hypertension. 2010;55(1):33-9. http://dx.doi.org/10.1161/ HYPERTENSIONAHA.109.138289. PMid:19996070

28. Kimura T, Yokoyama T, Matsumura Y, Yoshiike N, Date C, Muramatsu M, et al. NOS3 genotype-dependent correlation between blood pressure and physical activity. Hypertension. 2003;41(2):355-60. http:// dx.doi.org/10.1161/01.HYP.0000051500.02578.6D. PMid:12574107

29. Xi B, Cheng H, Shen Y, Zhao X, Hou D, Wang X, et al. Physical activity modifies the associations between genetic variants and hypertension in the Chinese children. Atherosclerosis. 2012;225(2):376-80. http://dx.doi. org/10.1016/j.atherosclerosis.2012.10.027. PMid:23102448

30. Leite N, Milano GE, Cieslak F, Lopes WA, Rodacki A, Radominski RB. Effects of physical exercise and nutritional guidance on metabolic syndrome in obese adolescents. Rev Bras Fisioter. 2009;13(1):73-81. http://dx.doi.org/10.1590/ S1413-35552009005000009.

\section{Correspondence \\ Rômulo Araújo Fernandes}

Universidade Estadual Paulista (UNESP)

Faculdade de Ciências e Tecnologia

Rua Roberto Simonsen, 305, Bloco III, Sala 05

CEP 19060-900, Presidente Prudente, SP, Brasil

e-mail: romulo@fct.unesp.br 